\title{
Respiratory Inhibitory Apraxia
}

\author{
E.A. ATACK AND LESLIE SURANYI
}

SUMMARY: Ten patients have been described showing inability to stop breathing on command, spontaneous respiration and voluntary respiratory stimulation being unaffected. This abnormality not previously described in the literature, we feel should be named respiratory inhibitory apraxia (R.I.A.). The anatomical organization of respiration is briefly reviewed. R.I.A. is often associated with other forms of apraxia or motor impersistence. It is thought that the urinary and bowel incontinence present in some of these

RÉSUMÉ: Dix patients ont été décrits comme montrant une incapacité d'arrêter de respirer sur commande. La respiration spontanée et la stimulation respiratoire volontaire êtaient normales. Nous pensons que cette anomalie devrait être nommée "Apraxie respiratoire inhibitrice" (A.R.I.). L'organisation anatomique de la respiration est revue brièvement. A.R.I. est souvent associée à d'autres formes d'apraxie ou à une impersistence motrice. On pense que l'incontinence urinaire et intestinale présente chez quelques-uns de ces cas cases might also represent a form of inhibitory apraxia. Information is presented which supports the view that respiratory inhibitory apraxia is due to a minor hemisphere lesion, usually deepseated. Our one autopsied case showed a lesion in the descending motor pathways in the internal capsule, in middle cerebral artery branch territory, disconnecting the voluntary respiratory inhibitory center in the cortex in anterior and middle cerebral cortical branch territories.

peut aussi représenter une forme d'apraxie inhibitrice. L'information présentée appuie fortement le point de vue que ce syndrome est dâ à une lésion mineure de l'hémisphère, lésion ordinairement localisée profondément. Notre seul cas autopsié montrait une lésion dans les fibres motrices descendantes au niveau de la capsule interne, dans le territoire de l'artère cérébrale moyenne, séparant ainsi le centre inhibiteur respiratoire volontaire du cortex en territoires dépendants des branches corticales antérieures et médicines.
From the Ottawa Civic Hospital.

A portion of this paper was presented at the annual meeting of the Royal College of Physicians and Surgeons, Montreal, Jan., 1974.

Reprint requests to Dr. E. A. Atack, 303-1081 Carling Ave., Ottawa, Canada K1Y 4G2.
Respiration is controlled by two systems. The metabolic system provides the automatic rhythmicity of respiration through the medullary and pontine respiratory centers (Wang \& Ngai, 1964; Mitchell \& Frohlich, 1972). Voluntary control is represented in the cortex (Oberholzer \& Togani, 1971; Kaada, 1971). The metabolic centers are influenced by the $\mathrm{O}_{2}$ and $\mathrm{CO}_{2}$ content of the blood and C.S.F. and the blood $\mathrm{pH}$. The changes are mediated by central and peripheral chemoreceptors. These two systems appear to be integrated, but how is not clear. Although many respiratory problems are not understood some things are known about the clinical abnormalities of respiratory rates and rhythms. (Fig. 1.) Respiratory apraxia - the inability to change the rhythmicity of respiration voluntarily, was described by Plum (1970) and Hebertson et al (1959, 1959). Plum observed fifteen patients with inability to take a deep breath or hold their breath on command. They were moderateiy de mented, had other abnormal neurological findings (inability to initiate swallowing, geganhalten, suck and snout reflexes) but were able to obey other commands. No pathological material is available from any of these patients, therefore localization is not possible. Herbertson et al (1959) described respiratory apraxia with Cheyne-Stokes respiration.

The purpose of this paper is to introduce a new abnormality of respiration that has not been described in isolation. This is the inability to voluntarily stop breathing, a disturbance which we have termed Respiratory Inhibitory Apraxia. We have studied ten patients and more recently have seen five additional patients who were able to change 
their respiratory rhythm by taking a deep breath on command or by singing or whistling and yet were unable to stop breathing on command. To assess comprehension and praxis all patients studied were given special non-respiratory and respiratory commands and the results were noted. The non-respiratory commands were "close your eyes and keep them closed", "open your mouth", "stick out your tongue", "touch your ear with your finger", and "lift up your head". The respiratory commands were "take a deep breath" and "whistle or sing". To test respiratory inhibition, the command "hold your breath" was used, and this on repeated occasions in each patient. Relatives and nurses were questioned about the patients' bowel or bladder incontinence. Handedness was noted in each case. All patients had a thorough neurological and general medical assessment including the testing of general and specific mental functions. All patients also had basic laboratory, radiological, E.E.G. and echoencephalographic investigations and in those in whom it appeared indicated, brain scan and angiography was carried out. No patient was included in our study unless it was clear to us (Figure 2) that the patient's inability to hold his breath on command was due to apraxia and not due to inability to understand the command.

\section{CASE REPORTS}

Case 1. N. A 64 year old right handed Chinese female was admitted with the sudden onset of throat pain, confusion and left hemiplegia. Examination, a few days after admission, revealed disorientation, somnolence, left hemiplegia, left upgoing toe and parietal inattention in the left arm and leg. She was also found to be unable to hold her breath and had periodic apraxia for eye closure and neck flexion. She had bladder and bowel incontinence. Investigation revealed a small, inferior wall, myocardial, infarction and the EEG was suggestive of a deep, right, cerebral destructive process. It was thought the neurological signs were the result of an embolus complicating a myocardial infarction.

She made a good recovery. She became able to move her left leg. The incontinence and inattention disappeared as well as the apraxia for eye closure and neck flexion. Respiratory inhibitory apraxia was not as noticeable after two months, but had not completely cleared.

Case 2. B.D. A 48 year old right handed male was admitted because of sudden, violent, headache, which was followed by confusion, left hemiparesis, bilateral grasp reflexes and a partial right third nerve palsy. C.S.F. examination revealed bloody fluid. Angiography showed an aneurysm in the region of the anterior communicating artery.

On re-examination ten months later he was disoriented, had a left hemiparesis, and bilaterally increased deep tendon reflexes. It was noted at this time that he was unable to hold his breath on command and was also unable to sustain eye closure and tongue protrusion. These abnormalities have persisted unchanged. The patient was not incontinent.

Case 3. J.B. A 75 year old right handed female was found unconscious in her home. Previous events were not known. On examination she was disoriented, had a left hemiparesis, gaze palsy to the left, and her tongue protruded to the left. She had hypalgesia in the left arm and leg, anosagnosia regarding her left arm, parietal inattention in her left leg and bilateral tone increase in the legs. She was incontinent of bladder and bowel. On further testing she had apraxia for eye closure and mouth opening and was not able to hold her breath. She had no difficulty in taking a deep breath, singing or whistling. Her EEG showed slow waves over the entire right hemisphere. The rest of her investigations were unremarkable. The recovery from her neurological disorder was moderate. She was not incontinent after the first week, but the respiratory inhibitory apraxia and the other findings persisted unchanged.

Case 4. D.H. A 61 year old right handed female was admitted because of confusion, right hemiparesis and aphasia. An angiogram at this time showed occlusion of the ascending fronto-parietal branches of the left middle cerebral artery. She was discharged much improved. She was alert, oriented and able to express herself.

Readmission was necessary six months later because she was found unconscious at home. She had a generalized seizure in the Emergency Department and was noted to be incontinent. Examination the next day revealed an alert, cooperative patient with dys- phasia and dysarthria, tone increase in both arms and both legs, bilaterally increased deep tendon reflexes and bilateral upgoing toes. On apraxia testing she was able to take a deep breath, but was not able to hold her breath and had apraxia for tongue protrusion and mouth opening. These findings could not be accounted for by impaired comprehension, as she was able to carry out the other requested actions listed above. Her EEG at this time showed bilateral slow wave abnormalities which were present only on the left side at the time of the previous admission. Angiograms were unchanged. Her general condition improved but the respiratory inhibitory apraxia persisted during her hospital stay.

Case 5. P.S. A 74 year old right handed male was admitted because of the sudden onset of left hemiplegia two months earlier. He had some improvement in motor function by the time of admission. On examination he was disoriented, had a left hemiparesis, increased deep tendon reflexes on the left, left upgoing toe, decreased pin sensation on the left, parietal inattention on the left and an almost absent corneal reflex on the left. Cn apraxia testing he was able to take a deep breath, but was not able to hold his breath and was not able to maintain eye closure. His EEG showed a slow and irregular background with superimposed episodic delta activity over the entire right hemisphere. The patient's findings were unchanged at subsequent examinations.

Case 6. C.N. This 65 year old right handed male was transferred from another hospital. He had been admitted because of head trauma sustained while drunk. Examination on admission revealed a somnolent, disoriented man with a dense left hemiplegia, left upgoing toe, gaze palsy to the left and questionable homonymous hemianopsia on the left. Lumbar puncture was done 2 days after admission and showed xanthochromic fluid. The patient was incontinent of urine. Respiratory inhibitory apraxia along with the inability to maintain eye closure and tongue protrusion was noted about a week after admission. (Testing was not done at the time of admission.) His EEG showed slow wave acitivity over the right temporal area. Brain scan showed increased uptake in the right frontal area. Follow-up was not obtained.

Case 7. J.L. A 72 year old right handed male was admitted because he collapsed and found he had no use of his left side afterwards. He was able to 
speak, but was complaining of not seeing well. He also had a right frontal headache. He had been seen by his family physician about two weeks before because of transient dizziness and transient loss of vision in his right eye. On examination he had a systolic ejection murmur over the apex, normal blood pressure $(160 / 90)$, left hemiparesis and hemianesthesia, left homonymous hemianopsia and a decreased left corneal reflex. There was also miosis on the right, deviation of the eyes to the left, dysarthria, increased deep tendon reflexes on the left with an upgoing toe, protrusion of the tongue to the left, neglect of his left side and a carotid bruit on the left side. He was confused and disorientated and incontinent of urine. On testing for apraxia he had complete apraxia for breath holding, partial for maintenance of eye closure, protrusion of the tongue, and lifting of the head. His cerebro-spinal fluid was normal. The EEG showed low-voltage background activity, with a slow wave abnormality mainly from the right fronto-temporal regions, but involving the whole hemisphere. Angiography revealed complete occlusion of the right internal carotid artery at its origin and narrowing of the left internal carotid artery at its origin. There was some shifting of the anterior cerebral artery branches to the left and some cross circulation from left to the right. He progressively deteriorated, became somnolent, but the respiratory inhibitory apraxia was present when aroused. He died three days after admission.

Pathology report: Gross: The hemispheres were asymmetrical. The right was expanded and showed a decrease in consistency. This corresponded to the middle cerebral arterial distribution. There was asymmetrical uncal herniation, more marked on the right. The vessels at the base of the brain showed little gross atherosclerosis, but were generally small. On the right, the internal carotid artery, together with the entire middle cerebral and the proximal $5 \mathrm{~mm}$ of the anterior cerebral artery showed antemortem thrombus. The left internal carotid artery and its branches were rather small. Serial gross sections confirmed the infarction and showed involvement of the claustrum, caudate, putamen, lateral pallidum, the upper part of the anterior limb of the internal capsule and the entire genu, posterior limb, retro-lenticular and sublenticular portions of the internal capsule. The thalamus, hypothalamus, and subthalamic areas appeared to be normal.
Microscopy: The sections confirmed a recent, acute infarction on the right side in the distribution of the middle cerebral artery. In addition there were focal lesions of the white matter, cortex, and thalamus on the left. These were suggestive of arterial insufficiency in boundary zones and perforating vessel areas, and were thought to be the result of the increase in intracranial pressure, just prior to death.

Case 8. G.F. A 64 year old Italian male was admitted on December 28, 1972. He had had left sided weakness three days prior to admission lasting fifteen minutes. He felt some weakness in his left arm and leg on the evening before admission. His wife noted that he was not able to move his left side during the night and he was hospitalized. On examination his blood pressure was 230/120 and his right carotid had decreased pulsation. He was confused and disoriented, had a left hemiplegia, left homonymous hemianopsia, absent left corneal reflex, absent sensation (touch, pin, vibration, position) on the left side, increased deep tendon reflexes on the left with absent left abdominal reflexes. He was incontinent of urine. He was unable to hold his breath, had motor impersistence for eye closure, tongue protrusion, mouth opening and head lifting. After transient deterioration his condition stabilized. There was no change in his inability to hold his breath, but his incontinence disappeared after a few weeks. The EEG showed irregular and lower voltage background activity on the right side, the angiogram revealed complete occlusion of his right internal carotid at its origin. The rest of his investigations were normal or not related to his neurological condition.

Case 9. K.M. A 58 year old male had intermittent numbness and weakness of his left arm lasting for $\mathbf{3 0}$ minutes. Two weeks after his first episode he woke with his left arm numb and weak. Physical examination revealed a plegic left arm, some ability to move his left leg, facial weakness on the left, visual inattention on the left and parietal lobe inattention in extremities on the left. The corneal reflex was decreased on the left and he was drowsy and confused.

He had respiratory inhibitory apraxia and impersistence of eye closure. Subsequently he was found to have a left homonymous hemianopsia and some decrease in pin sensation in the left arm. He was incontinent of urine and stool. The rest of the findings remained unchanged. His EEG showed slow wave abnormalities over the right hemisphere, the background being irregular on both sides, more on the right. Angiography was not done.

Case 10. J.L. A 76 year old male patient was admitted because of complete left hemiplegia which had developed gradually over a three hour period. On examination his blood pressure was normal. He was drowsy and disoriented, had a left homonymous hemianopsia, decreased left corneal reflex, and left hemiplegia. There was also impaired vibration and position sense on the left side, some impairment of pain in the left arm and parietal inattention in the left extremities plus dysarthria. He was unable to hold his breath or maintain eye closure. He was incontinent of urine. His EEG showed continuous slow wave disturbance on both sides, more over the right with a few runs of pointed sharp waves from the right. The rest of his investigations were negative.

\section{RESULTS}

The results of our investigations on the ten patients demonstrating respiratory inhibitory apraxia are listed in Figures 3-6. All ten patients were right handed and had right hemisphere lesions with left hemiplegia or hemiparesis. (Figure 3) Eight patients had ischemic vascular lesion, one had a ruptured aneurysm and one a presumed head injury. (Figure 4)

Seven of the ten patients had either a homonymous hemianopsia or pain impairment on the side of their upper motor neuron lesion suggesting deep-seated pathology. Five patients had impairment of their corneal reflex on the side of their hemiplegia. One autopsied case confirmed this, showing infarction of the internal capsule. (Figure 5) All ten patients had complete inability to hold their breath on command and all were able to take a deep breath, sing or whistle voluntarily. Three patients had apraxia for eye closure, mouth opening, tongue protrusion or neck flexion. Seven had motor impersistence for eye closure, four for tongue protrusion and two for head lifting and one for mouth opening. Eight patients seen at the onset of their illness had urinary incontinence and three had fecal incontinence. This was a transient abnormality in six of them. Two patients, not seen at the onset of their illness, 
did not show incontinence by the time they were admitted and it was not clear whether they had been incontinent prior to this. (Figure 6)

In six of the seven patients followed, the respiratory inhibitory apraxia did not improve over a period of one month to two years. The seventh changed from respiratory inhibitory apraxia, to motor impersistence, to breath holding.

\section{DISCUSSION}

Respiratory rhythmicity is assured by centers which are located at different levels of the brain stem. From the descriptions dealing with this subject the following structures seem to be important and the following functions attributed to them:

Pneumotaxic center: located in the rostral third of the pons, it is a paired structure and is probably the same as the locus ceruleus or the nucleus parabrachialis medialis. Transection of this part of the brain stem results in slowing of respiration with increase in amplitude. Its function is analogous with the nucleus ambiguus - nucleus parambiguus complex since either one is capable of maintaining eupnea. Section of the pneumotaxic center after vagotomy results in apneusis; cessation of respiration in the deep inspiratory state.

The apneustic center: a less precisely defined structure located in the middle and lower pons. It is thought to be responsible for apneusis since transection above it will cause apneusis, while transection below it will alter respiration. It remains rhythmic, but the amplitude changes and respiration becomes gasping.

The expiratory and inspiratory centers are not well demarcated structures and are a mixed mass of cells located under the caudal part of the fourth ventricle, close to the anterior and medial surface of the inferior olive. There is however, some distinction as the inspiratory center is deeper overlying the cephalic four-fifths of the inferior olive, while the expiratory center is more superficial, dorsal and rostral

\section{Type of Breathing}

A. Brain stem

Periodic breathing with changing amplitude

Fast deep breathing

Periodic breathing with no change in amplitude

Regular, deep, gasping respiration

Irregular respiration

No spontaneous, intact voluntary respiration

Decreased spontaneous, intact voluntary respiration

No voluntary but intact spontaneous respiration

\section{B. Cerebral}

Inability to change

breathing pattern

voluntarily

Figure I - Abnormalities of Respiration
A. Non-respiratory commands:

1. Close your eyes and keep them closed.

2. Open your mouth.

3. Stick out your tongue.

4. Touch your ear with your finger.

5. Lift up your head.

B. Respiratory commands:

I. Stimulation:

1. Take a deep breath.

2. Whistle.

3. Sing.

II. Inhibition:

1. Hold your breath.

Figure 2 - Method of testing patient for respiratory inhibitory apraxia.

to the inspiratory center. Stimulation of these centers results in a shift toward expiration or inspiration depending on the site of stimulation.

The nucleus ambiguus and retroambiguus are located lateral to the medullary centers. The discharge from the nucleus ambiguus is primarily related to inspiration. The rostrally placed cells in the nucleus retroambiguus are related to inspiration while the distally placed cells produce expiration.

Although the exact mechanism by which respiratory rhythm is attained is still unknown the structures described are essential in this regulation. There are multiple interconnections between them, influencing each other and also influenced by the chemical characteristics of the blood and cerebro-spinal fluid.

The work to define the anatomical substrate for the voluntary control of respiration is more recent and still incomplete. The relevant experiments were summarized by Kaada (1971), who did much of the experimental work. The location of the voluntary cortical centers is slightly different in man and primates, the difference being the result of change in the size and shape of the brain itself. There is a large area, stimulation of which inhibits respiration. The most important structures are the anterior cingulate gyrus, the posterior orbital surface, the anterior insula, amygdala, and the ventromedial aspect of the temporal 


\begin{tabular}{|c|c|c|c|c|}
\hline Initials & Age & Sex & Handedness & Hemiparesis \\
\hline 1. $\mathrm{N}$ & 64 & $F$ & $\mathbf{R}$ & Lett \\
\hline 2. B.D. & 48 & $\mathrm{M}$ & $\mathbf{R}$ & Left \\
\hline 3. J.B. & 75 & $\mathrm{~F}$ & $\mathbf{R}$ & Left \\
\hline 4. D.H. & 61 & $\mathrm{~F}$ & $\mathrm{R}$ & Bilateral \\
\hline 5. P.S. & 74 & M & $\mathbf{R}$ & Left \\
\hline 6. C.N. & 65 & $\mathbf{M}$ & $\mathbf{R}$ & Left \\
\hline 7. J.L. & 72 & M & $\mathrm{R}$ & Left \\
\hline 8. G.F. & 64 & $\mathbf{M}$ & $\mathbf{R}$ & Left \\
\hline 9. K.M. & 58 & M & $\mathbf{R}$ & Left \\
\hline 10. T.L. & 76 & $\mathbf{M}$ & $\mathbf{R}$ & Left \\
\hline
\end{tabular}

Figure 3 - Clinical data.

pole, particularly in the region of the uncus. The areas connecting these also give rise to inhibition, although to a lesser extent. The same applies to a small portion of the lower end of the precentral region over the lateral surface of the frontal lobe.

There are many areas in animals which on stimulation produce acceleration of respiration with increased, decreased or unaltered amplitude (motor cortex, anterior sylvian and ectosylvian gyri and the pyriform cortex). In man, only the middle and anterior portions of the cingulate cortex seem to have these characteristics.

Probably the least known components in the anatomical organization of respiration are the connections between the cortical centers and the lower structures in the brain stem and spinal cord. Attempts to trace the descending pathways by Marchi technique have shown these fibers coming from the cingulate gyrus through the internal capsule and the ventromedial part of the cerebral peduncle. At the rostral end of the pons the fibers leave the corticobulbar tract, and terminate in the medial reticular formation just below the superior olive (Wang and Ngai, 1964). During stereotaxic operations, with interference or destruction of the internal capsule and the ventro-lateral thalamus, respiratory depression has been achieved. This has been taken as indirect evidence that fibers from the cortex lie in the internal capsule. There is no direct evidence that fibers descend directly from the cortex.

The phenomenon called Ondine's curse (Severinphaus and Mitchell,
1962) i.e. patients with brain stem lesions or after ventromedial cordotomy at high cervical levels have able to maintain respiration voluntarily, plus the observation that after strokes the chest expansion on the opposite side was decreased (Plum, 1970), were also used as indirect evidence that these connections exist. These fibers supposedly descend through the corticospinal tract, cross the medulla and travel in the lateral funiculus to the ventral horn. It was also recently reported that phenoperidine used for anaesthesia abolishes spontaneous respiration leaving voluntary respiration intact. (Plum, 1970) This also favors the theory that voluntary and nonvoluntary fibers are dissociated. The voluntary system would constitute the third pathway affecting the anterior horn cells involved with respiration. The others are the fibers arising in the medial and lateral medullary centers.

It should also be mentioned that these fibers end on alpha motor no spontaneous respiration, but are

neurons, while the gamma motor system receives information from the respiratory muscles. Evidence for this is the fact that transection of the posterior roots at the thoracic level changes the respiratory volume (Mitchell and Frohlich, 1972).

There is clinical evidence that disorders of the extra-pyramidal system alter respiration, presumably through the gamma motor system.

\section{CONCLUSIONS}

From the information presented, the following conclusions may be drawn:

Respiratory inhibitory apraxia is found in some patients with minor hemisphere lesions. All of our patients presenting with respiratory inhibitory apraxia had minor hemisphere lesions. The major hemisphere was clinically intact or only mildly involved. The pathological findings of the one autopsied case showed only hypoxic changes on the left side, the result of an increase in intracranial pressure. In patient No. 4 the major hemisphere was origi-

Patient number and EEG findings
1. Deep destructive process on right

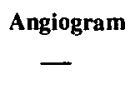

2. -

3. Slow wave disturbance on right

4. Bilateral slow wave disturbance

5. Slow wave disturbance on right

6. Slow waves over right temporal area

7. Slow wave disturbance on right

8. Low voltage, irregular on right

Anterior communicating aneurysm

Occlusion of left middle cerebral artery branches

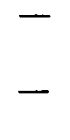

Occlusion of right internal carotid artery

Occlusion of right internal carotid artery

9. Slow wave disturbance on right

10. Bilateral slow waves, more on right side
C.S.F.

-

Bloody at the beginning

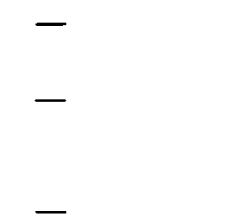

Xanthochromic Head trauma

Normal

Infarction

Infarction

Infarction

Infarction
Figure 4 - Investigations and diagnosis of ten patients with respiratory inhibitory apraxia. (- not done) 
nally involved but no respiratory inhibitory apraxia was observed until there was clinical and EEG evidence of minor hemisphere involvement. It appears that respiratory inhibition is represented in the minor hemisphere. None of our patients had major hemisphere lesions. Testing for respiratory inhibitory apraxia could not be carried out in patients with severe aphasic disturbances. However, in a number of patients with major hemisphere lesions with no aphasia or only mild aphasia, no respiratory inhibitory apraxia was found.

From the information at hand it seems that the lesion necessary to produce respiratory inhibitory apraxia is in the minor hemisphere and is deep-seated. It is important that all the cortical areas concerned with voluntary inhibition of respiration are located in the anterior and middle cerebral artery distribution. Therefore, a lesion involving the area supplied by the cortical branches of both of these arteries should theoretically result in respiratory inhibitory apraxia. None of our patients appear to be of this type. In our patients the deep seated lesion has interrupted the projection fibers from the cortical areas described and this has likely occurred in or near the internal capsule where these fibers are supplied by a branch or branches of the middle cerebral. This postulation is supported by the pathological findings in our seventh case in which the cortical areas that are said to be particularly important in respiratory inhibition (anterior cingular gyrus and posterior orbital surface) were unaffected while almost the whole internal capsule, and particularly the part containing descending motor pathways was infarcted. It seems likely, therefore, that the lesion responsible is a deep-seated one in most cases.

One of our patients, together with one not included above, showed a gradual change from respiratory inhibitory apraxia to motor impersistence for breath holding, suggesting a continuum between these two signs.

Bladder and bowel incontinence

\begin{tabular}{|c|c|c|c|c|}
\hline $\begin{array}{l}\text { Patient } \\
\text { Number }\end{array}$ & $\begin{array}{l}\text { Visual Field } \\
\text { Defect }\end{array}$ & $\begin{array}{l}\text { Corneal } \\
\text { Reflexes }\end{array}$ & $\begin{array}{c}\text { Hemi- } \\
\text { hypalgesia }\end{array}$ & $\begin{array}{c}\text { Sensory } \\
\text { Inattention }\end{array}$ \\
\hline 1. & Nil & Both present & Nil & Left \\
\hline 2. & Nil & Both present & Nil & Nil \\
\hline 3. & Nil & Both present & Left & Left \\
\hline 4. & Nil & Both present & Nil & $\mathrm{Nil}$ \\
\hline 5. & Nil & Absent left & Left & Left \\
\hline 6. & Left & Both present & $\mathrm{Nil}$ & Nil \\
\hline 7. & Left & Absent left & Left & Nil \\
\hline 8. & Left & Absent left & Left & Nil \\
\hline 9. & Left & Absent left & Left & $\begin{array}{l}\text { Left, plus } \\
\text { visual inattention }\end{array}$ \\
\hline 10. & Left & Absent left & Left & Left \\
\hline
\end{tabular}

Figure 5 - Physical findings suggesting deep seated lesions.

disappeared quickly compared to respiratory inhibitory apraxia. We conclude that this supports the previous evidence indicating bilateral cortical representation for these functions as opposed to unilateral representation, in the minor hemisphere, for voluntary respiratory inhibition. The fact that most of our cases of respiratory inhibitory apraxia also had urinary incontinence, suggests an anatomical relationship between the projection fibers for both functions.

Although we did not carry out any studies of bladder function, some cases described in the literature (Andrew and Nathan, 1964) presented with inability to stop urin- ating once started, and this might represent a form of inhibitory apraxia for control of bladder function.

\section{ACKNOWLEDGMENT}

We thank Dr. A. J. Lewis for providing the neuropathological description in the autopsied case.

\section{REFERENCES}

ANDREW, T. and NATHAN, P. W. (1964). Lesions of the Anterior Frontal Lobes and Disturbances of Micturition and Defecation. Brain 87: 233.

HEBERTSON, W. M., RICHARDSON, E. P. and CURRENS, J. $H$. et al (1959). Cheyne-Stokes Respiration, in Proceedings of the 6th International Conference, Brussels. London Perganon Press, pages 445 and 446.

\begin{tabular}{|c|c|c|c|}
\hline $\begin{array}{l}\text { Patient } \\
\text { Number }\end{array}$ & Other Apraxias & Motor Impersistence & Incontinence \\
\hline 1. & Eye closure,neck flexion & - & Bladder and bowel \\
\hline 2. & - & $\begin{array}{l}\text { Eye closure, tongue } \\
\text { protrusion }\end{array}$ & Unknown \\
\hline 3. & $\begin{array}{l}\text { Eye closure, mouth } \\
\text { opening }\end{array}$ & - & Bladder and bowel \\
\hline 4. & $\begin{array}{l}\text { Tongue protrusion, } \\
\text { mouth opening }\end{array}$ & - & Bladder \\
\hline S. & - & Eye closure & Unknown \\
\hline 6. & - & $\begin{array}{l}\text { Eye closure, tongue } \\
\text { protrusion }\end{array}$ & Bladder \\
\hline 7. & 一 & $\begin{array}{l}\text { Eye closure, tongue pro- } \\
\text { trusion, head lifting }\end{array}$ & Bladder \\
\hline 8. & - & $\begin{array}{l}\text { Eye closure, tongue pro- } \\
\text { trusion, mouth opening, } \\
\text { head lifting }\end{array}$ & Bladder \\
\hline 9. & 一 & Eye closure & Bladder and bowel \\
\hline 10. & - & Eye closure & Bladder \\
\hline
\end{tabular}


HEBERTSON, W. M., TALBERT, O. R., COHEN, M. C. (1959). Respiratory Apraxia and Anosognosia. Transactions of the American Neurological Association, pg. 176-179.

KAADA, B. A. (1971 reprint), Cingulate, Posterior Orbital, Anterior Insular and Temporal Pole Cortex. Chapter LV in Neurophysiology, Volume II. The Williams \& Wilkans Co., John Field, Editor. Baltimore.

MITCHELL, R. A. (1972). Control of Respiration. Chapter 6 in Pathophysiology. E. D. Frolich, Lippincott Company.
OBERHOLZER, R. T. H., TOGANI, W. O. (1971 reprint). The Neural Control of Respiration. Chapter XLIII in Neurophysiology, Volume II. The Williams \& Wilkans Co., John Field, Editor. Baltimore.

OJEMANN, G. A. and VAN BUREN, J. M., (1967). Respiratory, Heart Rate and GSR responses from Human Diencephalon. Archives of Neurology 16: 74-88.

PLUM, F. (1970). Neurologic Integration of Behavioural and Metabolic Control of Respiration. Hering-Brewer Centenary Symposium, Breathing. page 150-181. Edited by R. Porter, Churchill, London.
SEVERINPHAUS, T. W., MITCHELL, R. A. (1962). Ondine's Curse. Clinical Research 10:122.

SIEGFIELD, T., WEISENDANGER, M. (1967). Respiratory Alterations produced by Thalamic Stimulation during Stereotaxic Operation. Confinia Neurologica, 29, 220-223.

WANG, S. C., NGAI, S. H. (1964). General Organization of Central Respiratory Mechanisms. Handbook of Physiology, Respiration Volume I. 